University of South Carolina

Scholar Commons

6-1-2003

\title{
Links Between Snow Cover, Surface Skin Temperature, and Rainfall Variability in the North American Monsoon System
}

\author{
Toshi Matsui \\ University of South Carolina - Columbia \\ Venkataraman Lakshmi \\ University of South Carolina - Columbia, vlakshmi@geol.sc.edu \\ Eric Small
}

Follow this and additional works at: https://scholarcommons.sc.edu/geol_facpub

Part of the Earth Sciences Commons

\begin{abstract}
Publication Info
Published in Journal of Climate, Volume 16, Issue 11, 2003, pages 1821-1829.

Matsui, T., Lakshmi, V., \& Small, E. (2003). Links between snow cover, surface skin temperature, and rainfall variability in the North American monsoon system. Journal of Climate, 16 (11), 1821-1829.

(c) Copyright 2003 AMS
\end{abstract}

This Article is brought to you by the Earth, Ocean and Environment, School of the at Scholar Commons. It has been accepted for inclusion in Faculty Publications by an authorized administrator of Scholar Commons. For more information, please contact digres@mailbox.sc.edu. 


\title{
Links between Snow Cover, Surface Skin Temperature, and Rainfall Variability in the North American Monsoon System
}

\author{
Toshi Matsui and Venkat LaKshmi, \\ Department of Geological Sciences, University of South Carolina, Columbia, South Carolina \\ ERIC SMALL \\ Department of Earth and Environmental Science, New Mexico Tech, Socorro, New Mexico
}

(Manuscript received 29 March 2002, in final form 18 September 2002)

\begin{abstract}
The influence of land-atmosphere interactions on the variability of the North American monsoon system (NAMS) is investigated using the Television Infrared Observation Satellite (TIROS) Operational Vertical Sounder (TOVS) Pathfinder, the Climate Prediction Center (CPC) gauge precipitation, and observed snow water equivalent (SWE). Three hypotheses are tested regarding the connection between land surface variables and precipitation in the NAMS region. First, there is a weak negative correlation between 1 April SWE and subsequent surface temperature in the southern Rocky Mountains (SRM) region. However, this connection persists only until June and, therefore, cannot directly influence monsoon rainfall in July and August. Second, there is a negative correlation between SRM surface temperature and NAMS precipitation during the monsoon season, rather than the positive correlation previously proposed. Third, there is a highly significant negative correlation between rainfall and surface temperature within the NAMS region. On the monthly timescale, surface temperature decreases by $\sim 4 \mathrm{~K}$ per $1 \mathrm{~mm}$ day $^{-1}$ increase in rainfall, consistent with a positive soil moisture-rainfall feedback. The substantial variability of SRM skin temperature $(\sim 10 \mathrm{~K})$ may modulate the temperature gradient between land and ocean. However, these skin temperature anomalies persist only for $\sim 1$ month, so their effects are variable throughout the monsoon season.
\end{abstract}

\section{Introduction}

A large fraction of the annual precipitation in the southwestern United States and northwestern Mexico occurs during the period from early July through September (Douglas et al. 1993; Mock 1996). During these 3 months, $55 \%$ or more of the annual total precipitation falls in the southwestern United States while up to $\sim 80 \%$ falls in the Sierra Madre Occidental in Mexico (Douglas et al. 1993). This summertime precipitation maximum is produced by the monsoon system that extends from northwestern Mexico to the southwestern United States, referred to here as the North American monsoon system (NAMS; Fig. 1). The onset of monsoonal precipitation is abrupt, although the date of onset varies spatially, from mid-June in Mexico to the beginning of July in the southwestern United States (Higgins et al. 1998). Relatively heavy rainfall persists through July and August, and into September in some years.

Year-to-year fluctuations of summertime rainfall within the NAMS region are substantial. Accurate pre-

Corresponding author address: Dr. Venkat Lakshmi, Dept. of Geological Sciences, University of South Carolina, Columbia, SC 29233. E-mail:vlakshmi@geol.sc.edu dictions of these variations would help mitigate their negative impacts. These predictions require identifying the driving forces of the variability (Gutzler and Preston 1997). Higgins et al. (1998) found that precipitation variability in the NAMS region is linked to conditions in the eastern tropical Pacific-positive (negative) SST anomalies favor wet (dry) winter/spring conditions and dry (wet) summer conditions. Castro et al. (2001) found a relationship between NAMS variability and an SST index that combines the El Niño-Southern Oscillation and the North Pacific Oscillation regions. Interactions between the land surface and the atmosphere may also influence NAMS variability (Gutzler and Preston 1997; Gutzler 2000; Small 2001; Lo and Clark 2002). The land surface affects the atmosphere via the surface-atmosphere fluxes of water and energy. Soil moisture strongly controls the magnitude of these fluxes (Rowntree and Bolton 1983; Yeh et al. 1984; Entekhabi et al. 1992), so it may play an important role in modulating rainfall variability in the NAMS region.

Gutzler and Preston (1997) found a negative correlation between springtime snow cover in the southern Rocky Mountains (SRM; Fig. 2) and summertime rainfall in the northern portion of the NAMS region. They 


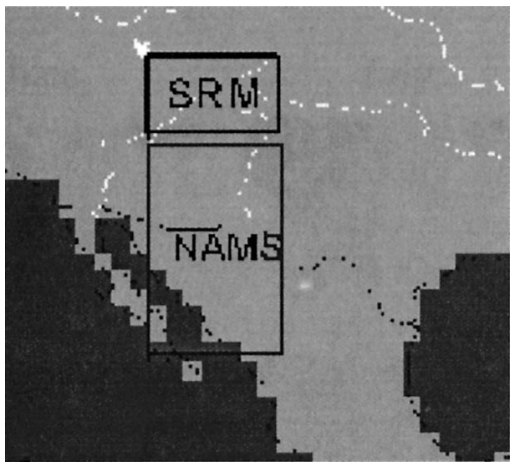

FIG. 1. Area definition and $1^{\circ}$ land mask for NAMS $\left(24^{\circ}-36^{\circ} \mathrm{N}\right.$, $\left.105^{\circ}-112^{\circ} \mathrm{W}\right)$ and SRM $\left(37^{\circ}-41^{\circ} \mathrm{N}, 105^{\circ}-112^{\circ} \mathrm{W}\right)$.

hypothesized that an above-normal SRM snowpack suppresses NAMS precipitation, analogous to the relationship between Eurasian snow cover and the Southeast Asian monsoon (e.g., Barnett et al. 1989). The hypothesized model is that above-normal snow cover lowers land surface temperatures, weakening the ocean-to-land temperature gradient that drives the North American and Southeast Asian monsoons. The influence of above-normal snowfall could last well into the monsoon season via persistence of the soil moisture reservoir, possibly due to later snowmelt or wetter soil subsequent to snowmelt (Gutzler and Preston 1997; Vernekar et al. 1995; Barnett et al. 1989). Abnormally wet soil raises the evaporation rate and increases the thermal inertia of the land surface, both of which would keep the land surface cooler than normal during summer months.

Gutzler (2000) completed an EOF analysis of the spatial patterns of rainfall and snow water equivalent (SWE) anomalies. He concluded that 1) the snowcoverrainfall link is strong between springtime SRM SWE and summertime rainfall in New Mexico, but not in Arizona; and 2) the link is strongest between 1961 and 1990. Lo and Clark (2002), using more spatially and temporally extensive data, also found that the characteristics of the relationship between SWE and NAMS rainfall vary through time. In contrast, they found a clear negative correlation between springtime SRM SWE and summertime rainfall anomalies in both Arizona and New Mexico.

An alternative explanation for the observed negative correlation between snowcover and subsequent rainfall is that both fields are correlated, but in opposite directions, with conditions in the Pacific Ocean (Higgins and Shi 2000; Mo and Paegle 2000). Small (2001) found that above-normal soil moisture (field capacity) over the southern Rocky Mountains inhibits precipitation in the NAMS region in a coupled land-atmosphere model. This result suggests that the statistical link between SRM spring snowcover and NAMS summer precipitation (Gutzler and Preston 1997) is physically reasonable, if the effects of an above-normal snowpack on soil moisture persists into the monsoon season. Small (2001) also found that above-normal soil moisture in the NAMS region enhances the simulated July precipitation within that area-a positive soil moisture-rainfall feedback exists (e.g., Eltahir 1998). The soil moisture anomalies prescribed in these simulations were rather strong, and further simulations with more realistic soil moisture variations are needed to corroborate these findings.

In this study, we use a variety of datasets, including remotely sensed surface temperature, to examine how land and atmosphere interact and modulate variability of NAMS rainfall. We test the following hypotheses:

1) Above-normal springtime SWE in the SRM is followed by below-normal surface temperatures in that region in subsequent months. If a negative correlation exists between these variables, then the pathway relating SRM snowcover to atmospheric heating at the northern end of the monsoon region is viable. A key element of this hypothesis is assessing if surface temperature anomalies, if any exist, are persistent enough to influence the summer monsoon in July and August.

2) During the monsoon season, above-normal surface temperature in the SRM yields above-normal monsoon precipitation. This is the proposed mechanism for how land surface conditions in the SRM influence NAMS precipitation.

3) There is a negative correlation between rainfall and surface temperature within the NAMS region, consistent with a positive soil moisture-rainfall feedback.

We rely on statistical correlations between different fields to test the proposed hypotheses. Of course, a correlation that supports the proposed hypotheses does not prove that they are accurate. The option that both variables respond to another (a third) driving variable cannot be ruled out. If the hypotheses are not supported, then we can conclude that the proposed link is negligible compared to other processes, such as an SST-driven large-scale circulation change (Castro et al. 2001) or eastern tropical Pacific SST anomalies (Higgins et al. 1998).

\section{Data and methods}

\section{a. Skin temperature}

The skin temperature data is taken from the Television Infrared Observation Satellite (TIROS) Operational Vertical Sounder (TOVS) dataset, which is $1^{\circ} \times 1^{\circ}$, gridded, with twice or several times daily frequency, depending on one or two satellites. The skin temperature is derived using the infrared-thermal channel 8,18 , and 19 of the High-Resolution Infrared Radiation Sounder instrument. The dataset (Susskind et al 1997) has been validated (Lakshmi et al. 1998; Lakshmi and Susskind 2000) for various land surface regions by direct comparison to surface temperature collected during field ex- 

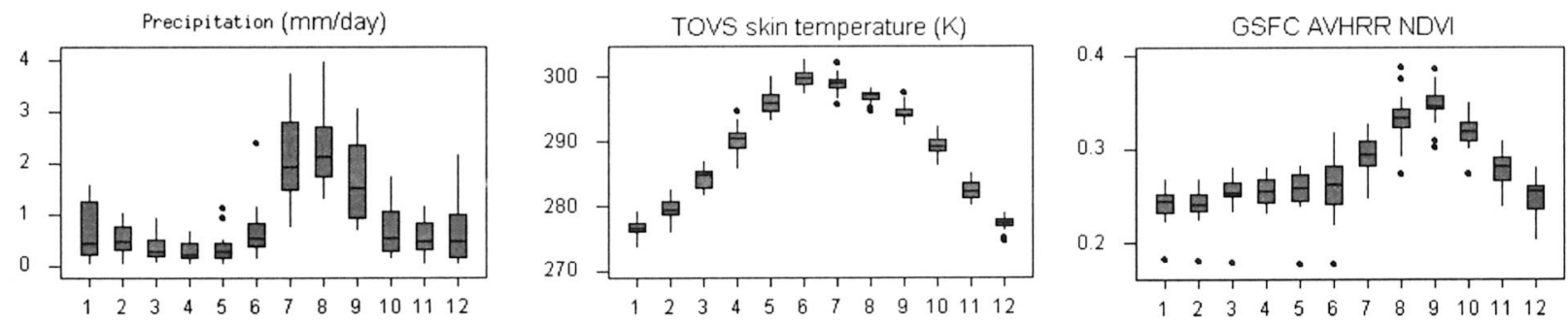

FIG. 2. Seasonal box plot of monthly (left) precipitation, (middle) TOVS $T_{s}$, and (right) AVHRR NDVI from 1979 to 2000.

periments. The results of these comparisons are that the two datasets (TOVS and in situ) have approximately zero mean difference. Although the bias is roughly zero, comparison of paired TOVS and in situ data yields a standard deviation of the difference due to the contrasting sampling regime: point measurements for in situ versus spatial average for satellite. This standard deviation is approximately $5 \mathrm{~K}$ and is remarkably constant over varied climates and geographical regions. The correlation between the monthly product of TOVS and in situ surface temperatures is in the range of 0.80 to 0.99 . These high correlations are reflective of the TOVS ability to correctly estimate the seasonal cycle of the surface temperature variations.

\section{b. Gauged precipitation}

The U.S. portion of analysis was based on the Climate Prediction Center (CPC) Unified Precipitation Dataset (Higgins et al. 1996). Approximately 13000 stations have reported each day since 1992, and approximately 8000 stations reported before 1992. The Mexican portion of the dataset was based on daily station data from approximately 200 stations prior to the 1990 and $\sim 600$ after. Precipitation in both the United States and Mexico was gridded with a resolution of $1^{\circ} \times 1^{\circ}$ by using the modified Cressman scheme.

\section{c. Snow water equivalent}

We used two different datasets to constrain variations in snow water equivalent in the southern Rocky Mountains. We use 1 April SWE from both datasets. Data from 1 April represent accumulation throughout the winter season. First, we used SWE measured at permanent snow course sites. For the period covered by the remote sensing data $(\sim 1979-2000)$, there were $\sim 250$ stations from the SRM region (Fig. 1) that reported 1 April SWE data. We average these data to construct a single index of SWE in the southern Rocky Mountains.

\section{d. Consistency of datasets}

Here we use the exact same SWE dataset in Lo and Clark (2001) to ensure consistency between our analyses. In addition, 1 April SWE was used in the previous studies (Gutzler 2000; Lo and Clark 2002) that found a significant negative link to NAMS precipitation. The rainfall dataset used here (CPC gridded) is also derived from the same station data that Lo and Clark (2002) used to produce their $2.5^{\circ} \times 2.5^{\circ}$ gridded data.

\section{e. Limitation of dataset availability}

It should be noted that the skin temperature is very sensitive to time of observation. We have used data from TOVS for a 16-yr period as we do not use data from $1980,1981,1987$, and 1988 so that only the 1530 local time (LT) overpass is used. CPC gridded gauged precipitation, which covered the United States and Mexico, are available from 1948 to 1999. Hence, 18- and 15-yr datasets are available for testing hypothesis 1 and hypotheses 2 and 3, respectively. Although the sample size used here is small, the results clearly show that the data do not support the proposed hypotheses, at least during the time period analyzed.

\section{f. Definition of NAMS and SRM regions}

The NAMS region is defined in Fig. 1, extending from $24^{\circ}$ to $36^{\circ} \mathrm{N}$ and $105^{\circ}$ to $112^{\circ} \mathrm{W}$. This region is based on NAMS region defined by Higgins et al. (1998) in their analysis of precipitation variability. The southern Rocky Mountain region is located between $37^{\circ}-41^{\circ} \mathrm{N}$ and $105^{\circ}-112^{\circ} \mathrm{W}$. Lo and Clark (2002) found the strongest correlation between SWE and NAMS summertime rainfall in this region, so we focus on it here.

\section{Results and discussion}

Summertime precipitation in the North American monsoon region is highly variable (Fig. 2). Variations exist on a broad range of timescales, from intraseasonal fluctuations to decade-long droughts and wet periods. In this study, we focus on year-to-year fluctuations in rainfall and how this variability is related to variations in land surface state in the NAMS and adjacent regions. We compare two examples each of wet years (1984 and 1990) and dry years (1994 and 1995) in Table 1 to illustrate the nature of interannual variability of rainfall and land surface conditions in this region. Averaged across the NAMS region, precipitation is twice as high in the selected wet years than in the dry years, with the 
TABLE 1. Comparison of precipitation, skin temperature, and NDVI between a wet year and a dry year in the NAMS.

\begin{tabular}{|c|c|c|c|c|c|c|c|c|c|c|c|c|}
\hline \multirow[b]{3}{*}{ Year } & \multicolumn{4}{|c|}{ Monthly precipitation $\left(\mathrm{mm} \mathrm{day}{ }^{-1}\right)$} & \multicolumn{4}{|c|}{ Monthly TOVS $T_{s}(\mathrm{~K})$} & \multicolumn{4}{|c|}{ Monthly NDVI } \\
\hline & \multicolumn{2}{|c|}{ Wet } & \multicolumn{2}{|c|}{ Dry } & \multicolumn{2}{|c|}{ Wet } & \multicolumn{2}{|c|}{ Dry } & \multicolumn{2}{|c|}{ Wet } & \multicolumn{2}{|c|}{ Dry } \\
\hline & 1984 & 1990 & 1994 & 1995 & 1984 & 1990 & 1994 & 1995 & 1984 & 1990 & 1994 & 1995 \\
\hline Jun & 1.3 & 0.2 & 0.1 & 0.1 & 306.5 & 315.0 & 309.2 & 311.9 & 0.273 & 0.241 & 0.262 & 0.261 \\
\hline Jul & 4.0 & 5.0 & 1.4 & 1.5 & 303.1 & 303.7 & 307.0 & 310.0 & 0.302 & 0.303 & 0.272 & 0.295 \\
\hline Aug & 4.3 & 3.6 & 1.8 & 2.4 & 301.5 & 302.2 & 304.0 & 304.9 & 0.339 & 0.387 & 0.273 & 0.293 \\
\hline Sep & 1.7 & 3.0 & 1.3 & 2.1 & 302.6 & 302.1 & 300.3 & 301.6 & 0.345 & 0.357 & 0.346 & 0.342 \\
\hline
\end{tabular}

greatest contrast in July and August. In 1984 and 1990, July precipitation is 4.0 and $5.0 \mathrm{~mm} \mathrm{day}^{-1}$, respectively, and August precipitation is 4.3 and $3.6 \mathrm{~mm}^{-1 a y}{ }^{-1}$, respectively. In contrast, July precipitation in 1994 and 1995 is 1.4 and $1.5 \mathrm{~mm} \mathrm{day}^{-1}$, respectively, and August precipitation is 1.8 and $2.4 \mathrm{~mm}^{-1 a y}{ }^{-1}$, respectively.

The influence of these year-to-year fluctuations in precipitation on monthly averaged surface temperature is dramatic, particularly in July. The averaged surface temperature in July is 303.1 and $303.7 \mathrm{~K}$ (1984, 1990, respectively) and 307.0 and $310.0 \mathrm{~K}$ (1994, 1995, respectively). Averaged over these selected years, this equates to a temperature lowering of $\sim 2 \mathrm{~K}$ for each 1 $\mathrm{mm}$ day $^{-1}$ increase in rainfall. This inverse correlation between surface temperature and rainfall reflects two processes: 1) rainfall and cloudiness are clearly linked, so above-normal rainfall is accompanied by diminished radiation input; and 2) rainfall enhances soil moisture, which lowers the Bowen ratio, leading to a decrease in surface temperature. Field data from the NAMS region show that the latter pathway is the primary reason why rainfall and temperature are inversely correlated in the environment examined here (Small and Kurc 2002).

The influence of rainfall variability on vegetation is also apparent, as exhibited by variations in monthly normalized difference vegetation index (NDVI). In the ex- ample wet years, NDVI is higher by up to 0.1 , which is a change that is more than half as large of the seasonal cycle of NDVI. Figure 3 shows the box and whisker plot of the extent of monthly variations in the abovementioned three variables, namely, precipitation, skin temperature, and NDVI over the 20-yr period (19792000). The monsoon season year-to-year variations in precipitation and NDVI are of similar magnitude or larger than the variations associated with the seasonal cycle. Surface temperature variations are also large. Given this variability, it is certainly possible that anomalies in land surface conditions could influence regional-scale atmospheric circulation.

\section{a. Relation between $S W E$ and subsequent $T_{s}$ in the SRM (hypothesis 1)}

The first hypothesis we test is that above-normal springtime snowpack in the SRM results in below-normal SRM surface temperature in subsequent months, and vice versa. There are several different physical pathways that could link the magnitude of the snowpack with subsequent surface temperature: 1) snowpack increases surface albedo (up to 0.6), leading to a decrease in surface net radiation; 2) snowmelt and sublimation enhance latent heat flux and lower sensible heat flux;
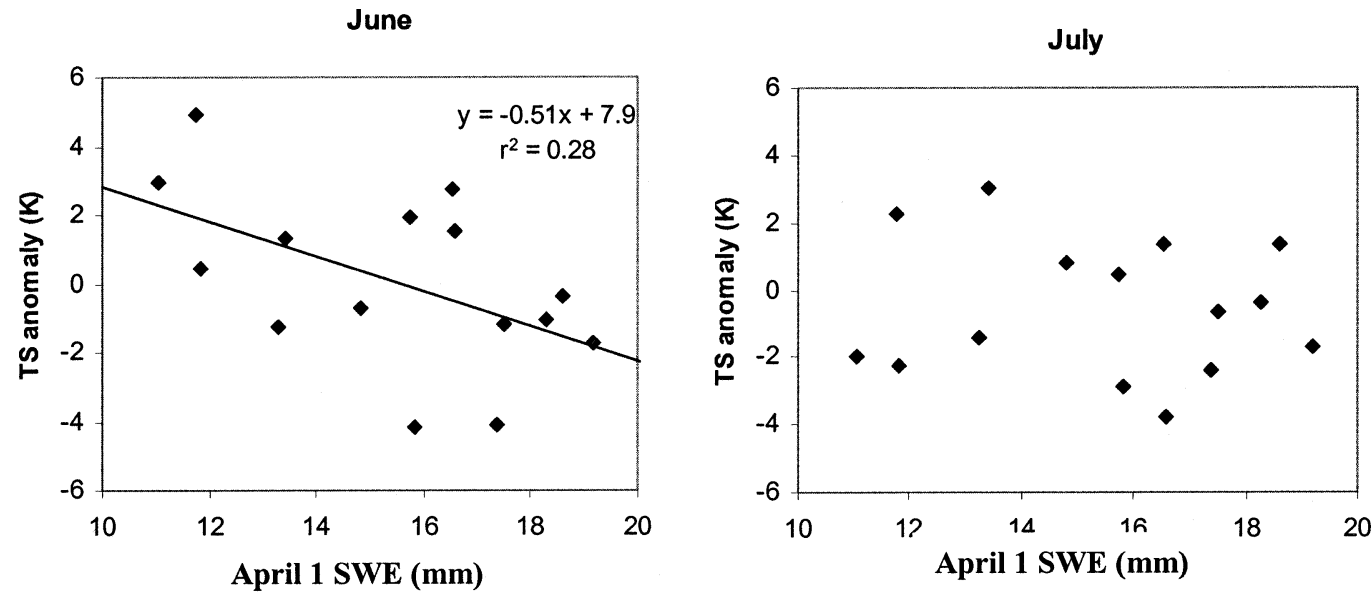

FIG. 3. Surface temperature anomalies vs $1 \mathrm{Apr}$ SWE in the SRM in (left) Jun and (right) Jul. Each point is $1 \mathrm{yr}$ between 1979 and 1997, excluding several years without $T_{s}$ data. The least squares linear fit to the data is included in the Jun plot, as the trend is significant at the $95 \%$ confidence level. There is no significant slope in Jul $\left(r^{2}=0.01\right)$ so a regression line is not included. 
TABLE 2. Results from regression between 1 Apr SWE and monthly averaged surface temperature in Apr-Sep $(N=18)$. SWE and surface temperature are averaged across SRM (see Fig. 1). Bold values show that the relationship is significant at the $95 \%$ confidence interval.

\begin{tabular}{lrrrrrr}
\hline \hline Observed SWE & Apr & May & Jun & Jul & Aug \\
\hline Slope $\left(\mathrm{k} \mathrm{mm}^{-1}\right)$ & -0.48 & -0.25 & $-\mathbf{0 . 5 1}$ & -0.08 & -0.11 \\
$r^{2}$ & 0.14 & 0.08 & $\mathbf{0 . 2 8}$ & 0.01 & 0.04 \\
\hline
\end{tabular}

and 3) snowmelt elevates soil moisture, increasing the thermal inertia of the land surface. Our goal is not to distinguish between these various pathways, but to see whether or not a negative correlation between snowpack and surface temperature exists. If it does exist, we must also identify the persistence of the link with respect to the timing of monsoon rainfall. If this relationship does hold and persists into the monsoon season, then an above-normal snowpack could weaken the ocean-land temperature gradient across the NAMS region influencing precipitation.

The relation between the 1 April snow water equivalent and the monthly skin temperature $\left(T_{s}\right)$ (1 AprilSeptember) over the 18 years is summarized in Table 2. There is a negative correlation between 1 April SWE and $T_{s}$ in April, May, and June: surface temperature is below normal from April to June when 1 April SWE is above normal (Table 2). In contrast, there is no clear relationship between SWE and subsequent surface temperature in July through September. Even though a negative correlation does exist from April through June, there is a large amount of scatter between SWE and $T_{s}$. The negative correlation is strongest in June (Fig. 3), when the negative slope is significant at the $95 \%$ confidence level. By July, there is no slope between $T_{s}$ and SWE (Fig. 3, Table 2). We also compared National Centers for Environmental Prediction (NCEP) SWE to SRM $T_{s}$ and found a similar result (not shown here). There is no relationship between NCEP SWE and TOVS $T_{s}$ from July to September, providing further proof that the proposed link does not exist.

Figure 4 shows the SRM $T_{s}$ anomalies for AprilSeptember (four values every year) and the correspond- ing 1 April SWE from NCEP. Note that the 1 April SWE is constant (i.e., the same for April-September), whereas the SRM $T_{s}$ changes. This time series shows that anomalous $T_{s}$ conditions are mostly inconsistent from April to September. For example, in 1983, there is an obvious negative correlation between SWE and $T_{s}$ at the beginning; however, the $T_{s}$ anomaly decreases in magnitude and eventually reverses sign by September.

We hypothesize that the inverse correlation between 1 April SWE and $T_{s}$ persists for several months maximum. The correlation may be stronger in June than earlier in the spring because most of the snowpack has melted by this time. There is substantial snow in April and May, so variations in SWE should not influence $T_{s}$ as the surface is snow covered regardless of SWE. By July and the onset of the NAMS, the influence of snow cover on SRM $T_{s}$ is negligible.

\section{b. Relationship between NAMS precipitation and SRM $T_{s}$ during the monsoon season (hypothesis 2)}

We now examine the hypothesis that above-normal SRM surface temperature yields above-normal precipitation in the NAMS region and vice versa. The proposed mechanism is that high SRM surface temperature enhances the ocean-land temperature gradient that drives the monsoon. If this hypothesis is accurate, we expect a positive correlation between SRM $T_{s}$ and NAMS precipitation (Fig. 4). Table 3 summarizes the results of regressions between monthly averaged SRM $T_{s}$ and monthly averaged NAMS precipitation. The relationship between SRM $T_{s}$ and NAMS precipitation is weak or nonexistent. Although the $r^{2}$ values $(\sim 0.12)$

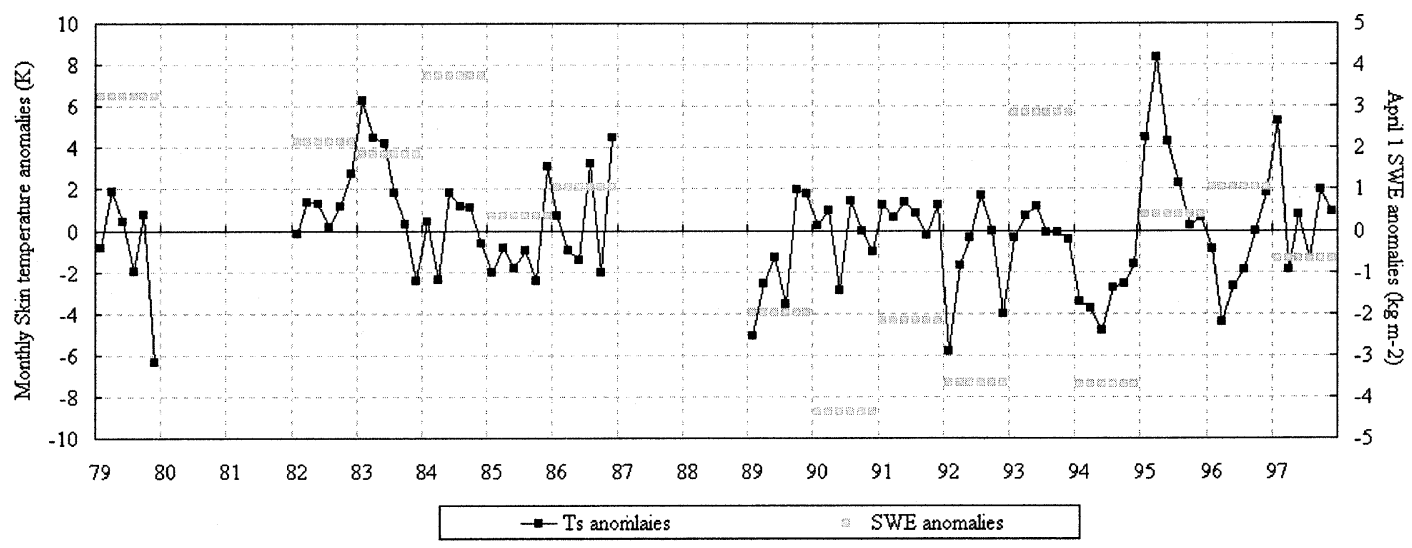

FIG. 4. Anomalies of SRM 1 Apr SWE and anomalies of SRM monthly skin temperature in Apr-Sep from 1979 to 2000. SWE values are on 1 Apr in each year. 
TABLE 3. Results from regression between SRM surface temperature and NAMS precipitation. Monthly averaged values are used. None of the relationships are significant at the $95 \%$ confidence level.

\begin{tabular}{llrrc}
\hline \hline & Jun & Jul & Aug & Sep \\
\hline Slope $\left(\mathrm{mm} \mathrm{day}^{-1} \mathrm{~K}^{-1}\right)$ & 0.0065 & -0.15 & -0.15 & -0.077 \\
& 0.00 & 0.10 & 0.08 & 0.12 \\
\hline
\end{tabular}

are low, the slopes of the regressions suggest that a weak negative relationship may exist between July and September, not a positive relationship as predicted by hypothesis 2. This weak negative correlation between SRM $T_{s}$ and NAMS precipitation is apparent, at least in 1984 (wet) and 1994 (dry), in the time series of monthly averaged SRM $T_{s}$ and NAMS precipitation (Fig. 5). Note that seasonal changes in SRM $T_{s}$ anomalies are accompanied by those in the NAMS precipitation anomalies (Fig. 5).

As shown by Gutzler (2000) and Lo and Clark (2002), the nature of the link between SRM snowcover and NAMS rainfall strongly depends on the portion of the NAMS examined. To ensure that the negative SRM $T_{s}-$ NAMS precipitation correlation shown in Table 3 was not an artifact of the NAMS region we selected, we plotted the regression between average SRM $T_{s}$ and rainfall at each point throughout the analysis region (Fig. $6)$. In July-September, there are weak negative correlations (blue) between SRM $T_{s}$ and rainfall at any point throughout the NAMS region. One location is an exception: there is a positive correlation between SRM $T_{s}$ and July precipitation in the northeastern corner of the NAMS region (New Mexico). However, the $r^{2}$ values of this slope are $<0.1$, so this relationship is weak at best. In July, this corner of the NAMS region is the westernmost extension of a broad region where rainfall is positively linked (red) to SRM surface temperature with high $r^{2}$ values $(>0.4)$.

We now investigate why there is a negative correlation between SRM surface temperature and NAMS precipitation, the opposite of what is expected based on hypothesis 2. Figure 7 shows relationships between NAMS-averaged precipitation and precipitation throughout the analysis region. Positive correlation (red) region includes the SRM with relatively high $r^{2}$ value $(\sim 0.4)$, which is significant at the $95 \%$ confidence level. The border between positive (red) and negative (blue) correlation shows that evolution of the NAMS precipitation extends to the SRM. Strong, local, negative correlation ( $r^{2}$ value $\sim 0.7$ ) exists between surface temperature and precipitation anomalies within a region (section 3c). Therefore, the observed negative correlation between SRM $T_{s}$-NAMS precipitation can be explained by the combination of 1) coherent horizontal structure of precipitation anomalies over SRM and NAMS and 2) local influence of rainfall on the surface skin temperature.

\section{c. Relationship between NAMS precipitation and surface temperature (hypothesis 3)}

We now examine the relationship between precipitation and surface temperature within the NAMS region. If a negative correlation exists, then the data are consistent with the presence of a positive soil moisturerainfall feedback: higher rainfall $\rightarrow$ higher soil moisture $\rightarrow$ lower surface temperature $\rightarrow$ higher net radiation $\rightarrow$ higher probability of rainfall occurrence (e.g., Eltahir 1998). Field observations from the northern end of the NAMS region support this hypothesis (Small and Kurc 2002). However, its importance on a regional scale is unknown. Here, we can only check the proposed negative correlation between rainfall and surface temperature, as multiyear records of regional soil moisture from remote sensing platforms do not yet exist. Examining the local relationship between rainfall and surface temperature also is critical to understand the results presented in section $3 \mathrm{~b}$.

Rainfall and surface temperature averaged throughout the NAMS region are negatively correlated (Table 4, Fig. 8). The slope of the regression is roughly

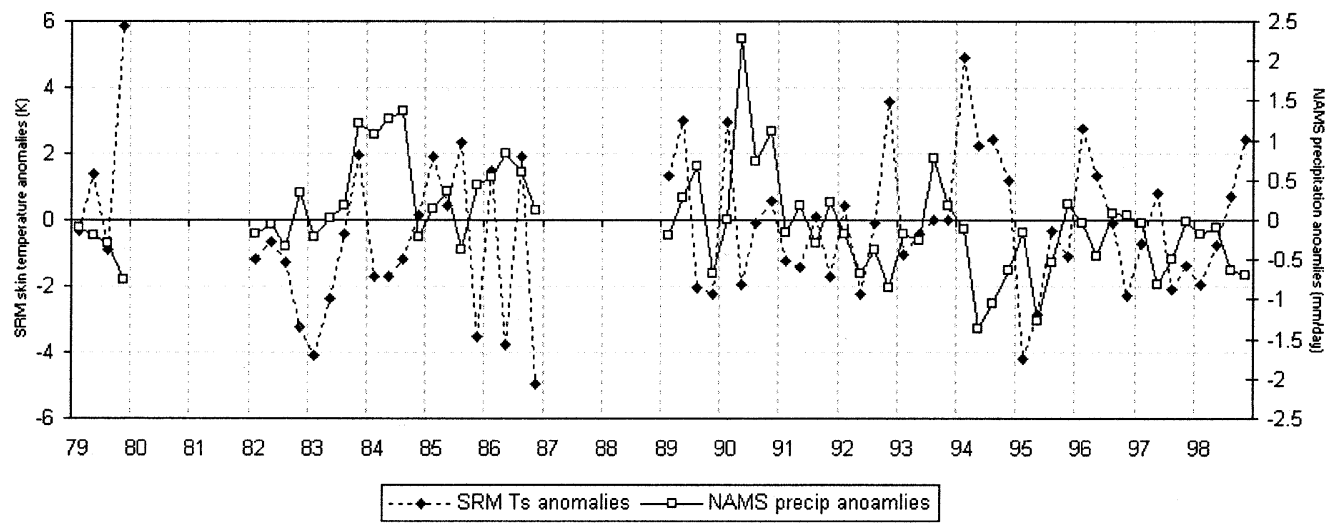

FIG. 5. Anomalies of SRM monthly skin temperature (K) and anomalies of NAMS monthly precipitation (mm day $^{-1}$ ) in Jun, Jul, Aug, and Sep from 1979 to 2000. SRM skin temperature and NAMS precipitation exhibit clear negative relationships in 1984 (wet year) and 1994 (dry year). 


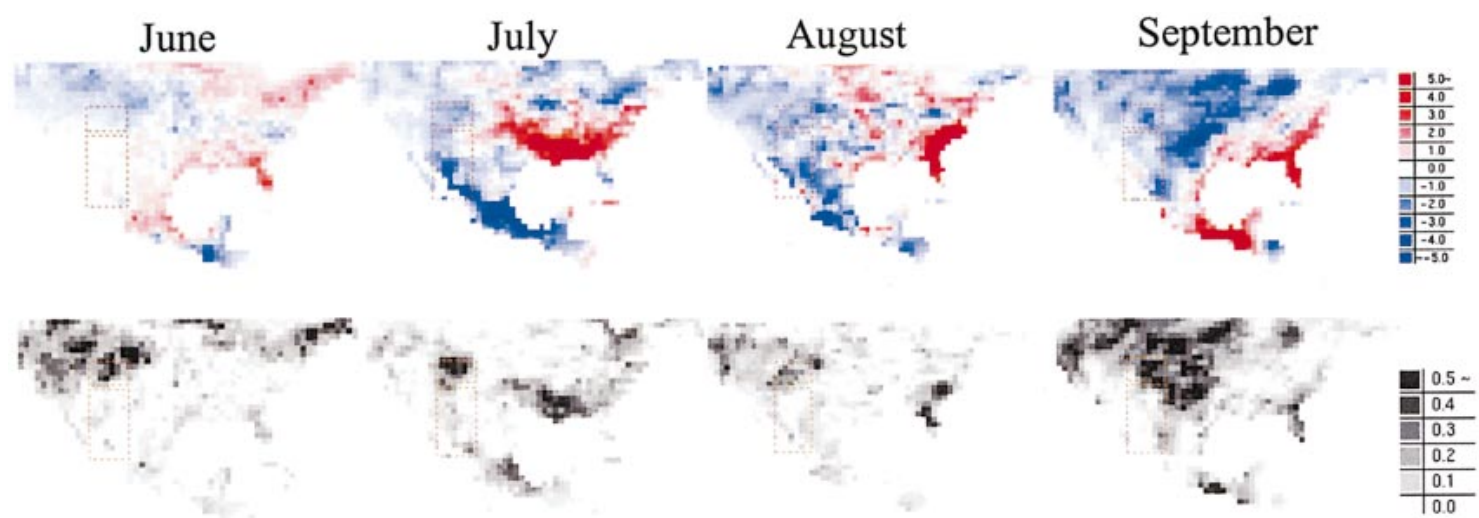

FIG. 6. Relationship between surface temperature averaged in the SRM and gridded precipitation throughout the analysis region. (top) Slope of the regression and (bottom) $r^{2}$ values. Most of the NAMS region is negatively (blue) correlated to SRM skin temperature anomalies.

$-4 \mathrm{~K}\left(\mathrm{~mm} \text { day }^{-1}\right)^{-1}$ during July and August. These are reasonable numbers given the observed linkages between soil moisture and surface temperature (Betts and Ball 1998; Small and Kurc 2002). The slope is very highly negative in June, due to the very limited rainfall during this month, and may not be realistic. The negative correlation is significant at the $95 \%$ confidence level in June-August. It makes sense that this relationship is much stronger than the other two examined in this paper, as it does not rely upon teleconnections (SRM $T_{s}$ and NAMS rainfall) or persistence of soil moisture anomalies (SRM SWE and $T_{s}$ ).

As expected, the strong negative correlations and high $r^{2}$ value slopes are observed across the entire analysis region (Fig. 9) except in September. The strongest $r^{2}$ values $(=0.7)$ are seen for the Ohio River valley, but the response in this region is not dramatic $[-2 \mathrm{~K}(\mathrm{~mm}$ day $\left.{ }^{-1}\right)^{-1}$, probably due to limited bare soil evaporation and deep rooting zones. The slopes are positive in portions of the western United States and part of the NAMS region in September. The calculations in these regions may be unrealistic due to low rainfall amounts. This is a target for future investigation.

\section{Discussion and conclusions}

Springtime SWE (1 April) and surface temperature (April-June) in the southern Rocky Mountains shows a negative correlation (Table 2), as hypothesized. However, this negative relationship does not persist into the monsoon season. Between July and September, there is no correlation between surface temperature and SWE from the preceding 1 April. This result suggests that the persistence of soil moisture anomalies in the southern Rocky Mountains region is on the order of only 1 or 2 months, as snow has melted at most elevations by the end of May. Surface-based observations are necessary to confirm this result. Regional-scale soil moisture monitoring via satellite platforms would also provide the data necessary to estimate the duration of soil moisture
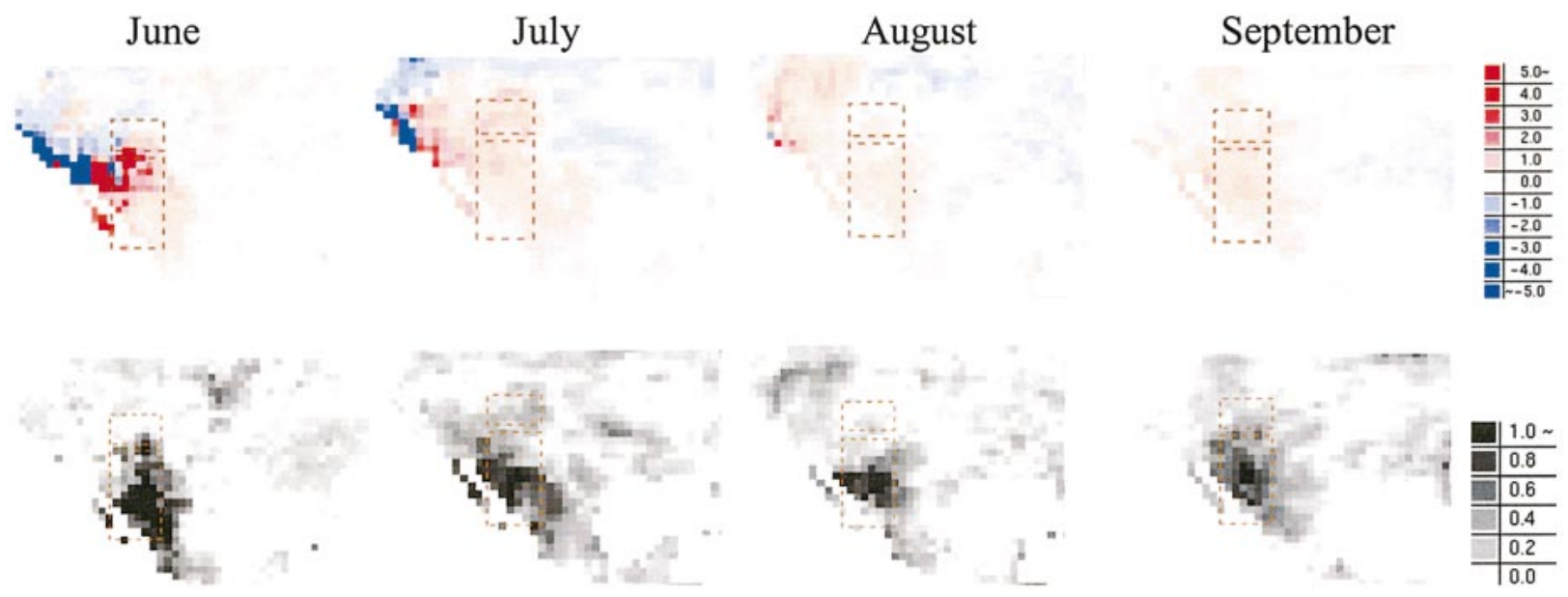

FIG. 7. Relationship between NAMS-averaged precipitation and precipitation at each $1^{\circ} \times 1^{\circ}$ cell throughout the analyzed region. (top) Slope of the regression and (bottom) $r^{2}$ values. 
TABLE 4. Results from regression between monthly averaged NAMS precipitation and monthly averaged NAMS surface temperature $(N=18)$. Bold values show that the trend is significant at the $95 \%$ confidence interval.

\begin{tabular}{lcccc}
\hline \hline & Jun & Jul & Aug & Sep \\
\hline Slope K $\left(\mathrm{mm} \mathrm{day}^{-1}\right)^{-1}$ & $\mathbf{- 1 2 . 7}$ & $\mathbf{- 4 . 6}$ & $\mathbf{- 4 . 1}$ & -7.8 \\
$r^{2}$ & $\mathbf{0 . 3 3}$ & $\mathbf{0 . 3 9}$ & $\mathbf{0 . 3 7}$ & 0.18 \\
\hline
\end{tabular}

and surface temperature anomalies resulting from above- or below-normal SWE.

The second hypothesis is not supported by our analysis. During the monsoon season, a negative correlation exists between SRM surface temperature and NAMS rainfall, rather than the proposed positive correlation. The observed negative correlation reflects the combined effects of two different mechanisms: 1) summertime precipitation in the SRM and NAMS regions are positively correlated; and 2) rainfall and surface temperature are strongly negatively correlated throughout the analysis region. Our result shows that these two processes are statistically significant at $95 \%$ confidence level.

Our results with regard to hypotheses 1 and 2 are not conflicting with the SRM SWE-NAMS rainfall relationship found by Gutlzer and Preston (1997), Gutzler (2000), and Lo and Clark (2002). The link between SRM snowcover and NAMS rainfall strongly depends on the portion of the NAMS examined (Gutzler 2000; Lo and Clark 2002). The $1^{\circ} \times 1^{\circ}(\sim 100 \mathrm{~km} \times 100 \mathrm{~km})$ gridded data used in this paper may not be adequate to describe subgrid rainfall variabilities. Indeed, current remotely sensed datasets are available from 1979, which includes neither a number of historical wet and dry years in the NAMS nor most of the strong correlation period during 1961-90 mentioned by Gutzler (2000). We have examined the mechanism linking SRM 1 April SWE and summertime NAMS precipitation by independently testing step-by-step the proposed correlation: SRM SWE $\rightarrow$ SRM $T_{s} \rightarrow$ precipitation in the NAMS region. This study shows that the SWE-precipitation connection is negligible, at least compared to the strong covariance between precipitation anomalies in the SRM and NAMS regions.

The factor that influences the surface temperature is the local precipitation and the magnitude of this response statistically overwhelms any possible relationships between land surface temperature in one location and their influence on precipitation in adjacent regions through physical teleconnections. It also overwhelms the influence of SWE several months earlier. The monthly surface temperature anomalies are linked to precipitation on the order of $2-4 \mathrm{~K}\left(\mathrm{~mm} \mathrm{day}^{-1}\right)^{-1}$. The observed strong local connection between rainfall and surface temperature is consistent with a positive soil moisture rainfall feedback (e.g., Eltahir 1998; Betts and Ball 1998). This sort of local interaction could play a strong role in rainfall variability (spatial and temporal) in the region.

The snowpack-driven $T_{s}$ anomalies in the SRM are short-lived; however, this study shows that its magnitude is considerably high $(\sim 10 \mathrm{~K})$, which could modulate the $T_{s}$-SST gradient on monthly or shorter timescales. This paper portrays the relationship between $T_{s}$, SWE, and precipitation over $16 \sim 18 \mathrm{yr}$. Although our analysis is not relevant over the range of climatic conditions that exist on longer timescales, our results demonstrate the key relationship between the land surface and atmosphere in the NAMS region. Most of those relations hold statistical significance at the $95 \%$ confidence level. These mechanisms could play an important role in understanding the monsoon development. The difficult challenge in the future is to compare possible linkages in monsoonal precipitation and quantify:

1) local feedbacks between rainfall, soil moisture, surface temperature, and their influence on radiation budgets and boundary layer dynamics;

2) teleconnections between land surface conditions in one region and their influence on precipitation in another region through atmospheric dynamics;

3) influence/teleconnections between sea surface tem-

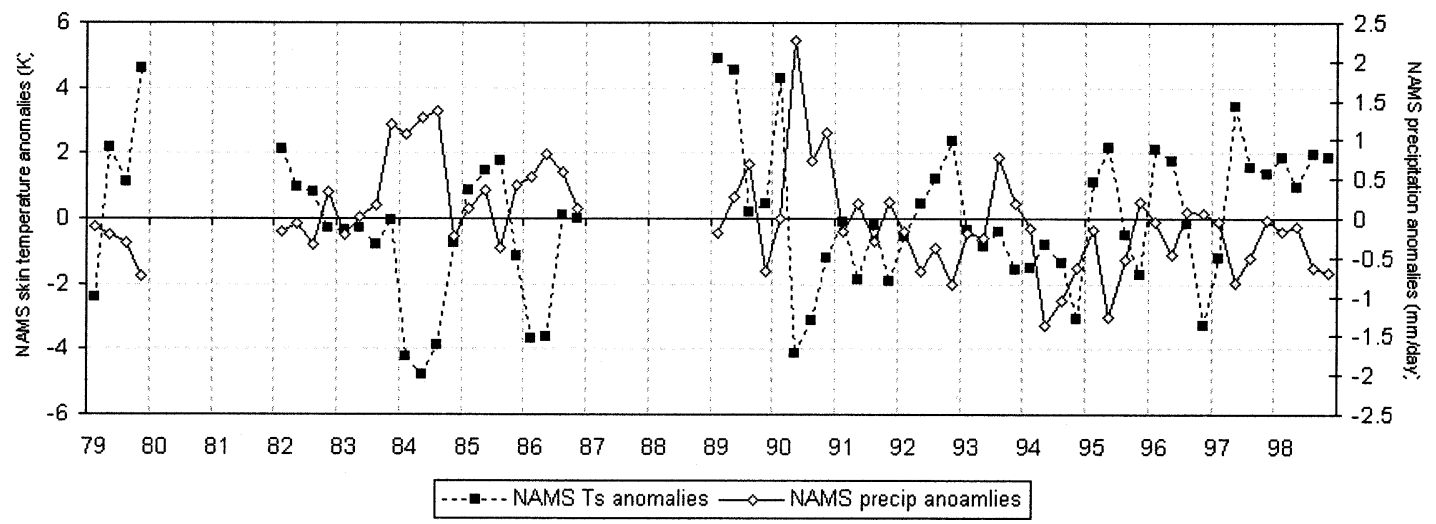

FIG. 8. Anomalies of NAMS monthly skin temperature (K) and anomalies of NAMS monthly precipitation (mm day ${ }^{-1}$ ) in Jun, Jul, Aug, and Sep from 1979 to 2000 
June
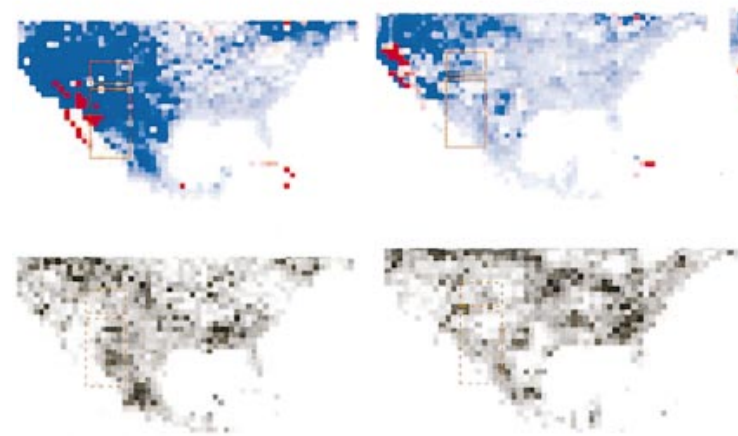

July

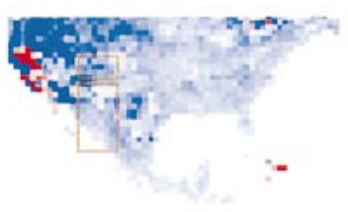

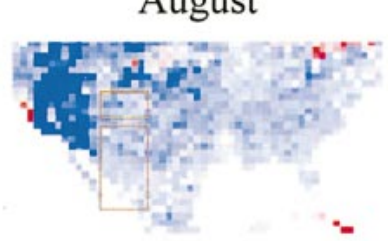
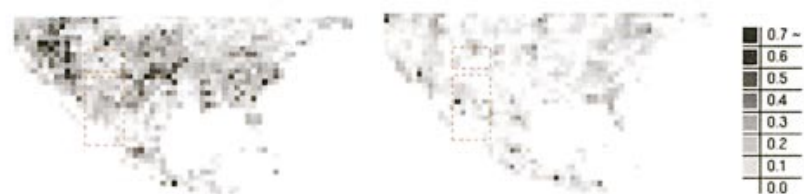

FIG. 9. Relationship between gridded monthly average precipitation and monthly average surface temperature at each point within the analysis region. (top) Slope of the regression and (bottom) $r^{2}$ value.

perature and monsoonal precipitation over continental land surfaces.

Future work in this area will help in discerning the varied contributions from the land surface and the ocean in regulating rainfall variability in areas like the NAMS region. These studies will be a combination of simulations and observational analysis.

Acknowledgments. This work has been funded by NAG59233 (University of South Carolina) and NAG59328 (New Mexico Tech) from the NASA Earth Science Enterprise. Our thanks to Dr. Diane Wickland, Program Manager at NASA HQ.

The authors thank Dr. Joel Suskind, Ms. Lena Iredell for the TOVS pathfinder data, and Dr. Compton Tucker and Ms. Molly Brown for the GSFC AVHHR NDVI product. The authors also thank Martyn Clark for providing the snow course SWE data in an easily usable format.

\section{REFERENCES}

Barnett, T. P., L. Dumenil, U. Schlese, E. Rockner, and M. Latif, 1989: The effect of Eurasian snow cover on regional and global climate variations. J. Atmos. Sci., 46, 661-685.

Betts, A. K., and J. H. Ball. 1998: FIFE surface climate and siteaveraged dataset 1987-89. J. Atmos. Sci., 55, 1091-1108.

Castro, L. C., T. B. McKee, and R. A. Pielke Sr., 2001: The relationship of the North American monsoon to tropical and North Pacific surface temperatures as revealed by observational analyses. J. Climate, 14, 4449-4473.

Douglas, M. W., R. A. Maddox, K. Howard, and S. Reyes, 1993: The Mexican monsoon. J. Climate, 6, 1665-1677.

Eltahir, E., 1998: A soil moisture-rainfall feedback mechanism. 1. Theory and observations. Water Resour. Res., 34, 765-776.

Entekhabi, D., I. Rodriguez-Iturbe, and R. Bras, 1992: Variability in large-scale water balance and land surface-atmosphere interaction. J. Climate, 5, 798-813.

Gutzler, D., 2000: Covariability of spring snowpack and summer rainfall across the Southwest United States. J. Climate, 13, 40184027.
—_ and J. Preston, 1997: Evidence for a relationship between spring snow cover in North American and summer rainfall in New Mexico. Geophys. Res. Lett., 24, 2207-2210.

Higgins, R. W., and W. Shi, 2000: Dominant factors responsible for interannual variability of the summer monsoon in the southwestern United States. J. Climate, 13, 759-776.

_- J. E. Janowiak, and Y.-P. Yao, 1996: A gridded hourly precipitation data base for the United States (1963-1993). NCEP/Climate Prediction Center Atlas 1, National Centers for Environmental Prediction, $46 \mathrm{pp}$.

_ - K. C. Mo, and Y. Yao, 1998: Interannual variability of the U.S. summer precipitation regime with emphasis on the southwestern monsoon. J. Climate, 11, 2582-2606.

Lakshmi, V., and J. Susskind, 2000: Validation of TOVS land surface parameters using ground observations. J. Geophys. Res., 105 (D2), 2179-2190.

,-- , and B. J. Choudhury, 1998: Determination of land surface skin temperatures, surface air temperature and humidity from TOVS HIRS2/MSU data. Adv. Space Res., 22, 629-636.

Lo, F., and M. Clark, 2002: Relationship between spring snow mass and summer precipitation in the southwestern United States associated with the North American monsoon system. J. Climate, 15, 1378-1385.

Mo, K. C., and J. N. Paegle, 2000: Influence of sea surface temperature anomalies on the precipitation regimes over the southwestern United States. J. Climate, 13, 3588-3598.

Mock, C. J., 1996: Climatic controls and spatial variations of precipitation in the western United States. J. Climate, 9, 1111-1125.

Rowntree, P. R., and J. A. Bolton, 1983: Simulation of the atmospheric response to soil moisture anomalies over Europe. Quart. J. Roy. Meteor. Soc., 109, 501-526.

Small, E., 2001: The influence of soil moisture anomalies on variability of the North American monsoon system. Geophys. Res. Lett., 28 (1), 139-142.

- and S. Kurc, 2002: The influence of soil moisture on the surface radiation budget, ground heat flux, and soil temperature in semiarid grassland and shrubland ecosystems. Water Resour. Res., in press.

Susskind, J., P. Piraino, L. Rokke, L. Iredell, and A. Mehta, 1997: Characteristics of the TOVS Pathfinder Path A data set. Bull. Amer. Meteor. Soc., 78, 1449-1472.

Vernekar, A. D., J. Xhou, and J. Shukla, 1995: The effect of Eurasian snow cover on the Indian monsoon. J. Climate, 8, 248-266.

Yeh, T. C., R. T. Wetheraald, and S. Manabe, 1984: The effect of soil moisture on the short-term climate and hydrology change-A numerical experiment. Mon. Wea. Rev., 112, 474-490. 